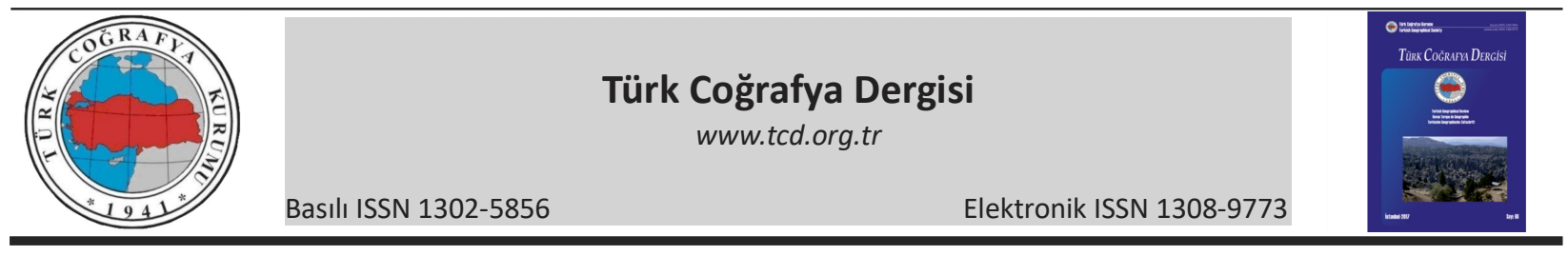

\title{
Türkiye'de su kıtlığının mekânsal ölçekte değerlendirilmesi
}

\author{
Assessment of water scarcity at spatial scale in Turkey \\ Olgu Aydın*a Ülkü Eser Ünaldı ${ }^{\text {, }}$ Neşe Dumanc, İhsan Çiçek ${ }^{a}$, Necla Türkoğlua \\ ${ }^{a}$ Ankara Üniversitesi, Dil ve Tarih-Coğrafya Fakültesi, Coğrafya Bölümü, Ankara. \\ ${ }^{b}$ Gazi Üniversitesi, Eğitim Fakültesi, Coğrafya Bölümü, Ankara. \\ 'Çankırı Karatekin Üniversitesi, Edebiyat Fakültesi, Coğrafya Bölümü, Çankırı.
}

\section{MAKALE BILGI}

Geliş/Received: 08.11.2016 Kabul/Accepted: 15.02.2017

Anahtar Kelimeler:

Yağış

Havza

Su potansiyeli

Falkenmark su stresi indisi

Keywords:

Precipitation

Basin

Water potential

Falkenmark water stress index

*Sorumlu yazar/Corresponding author (O.Aydın) oaydin@ankara.edu.tr

http://dx.doi.org/10.17211/tcd.314754

\section{ÖZ / ABSTRACT}

Su, dünyanın en önemli doğal kaynaklarından biridir. Hızlı nüfus artışı, kentleşme ve sanayileşme suya olan talebi her geçen gün artırmaktadır. Bu durum yakın gelecekte ülkelerin su kaynaklarına ulaşmasında büyük problemlere neden olacaktır. Gelecekte yaşanması muhtemel su sıkıntısına karşı alınabilecek önlemlerin planlanmasında, ülkelerin su potansiyellerini doğru hesaplanması gerekmektedir. Su potansiyelinin belirlenmesinde en önemli faktör, mekânsal ve zamansal ölçekte değişkenlik gösteren yağıştr. Yağışın doğru tahminini yapabilmek ve mekânsal dağılımını ortaya koymak zordur. Bu zorluğu aşmak ve yağışı doğru tahmin etmek için farklı yöntemler kullanılmaktadır. Bunlar arasında en fazla tercih edilen jeoistatistik yöntemlerdir. Jeoistatistik yöntemler kullanılarak gerçekleştirilen bu çalışmanın amaçları; Türkiye'nin yağışını gerçeğe uygun hesaplamak, doğru yağış tahmin modelini oluşturmak, her bir havza için yıllık ortalama toplam yağış miktarını hesaplamak, 26 havzada kişi başına düşen su miktarını belirlemek ve her bir havzayı Falkenmark su stres indisine göre değerlendirmektir. Bu amaçla çalışmada 1975-2010 dönemini kapsayan yıllık ortalama toplam yağış verisi ve 26 akarsu havza sınırları içerisine düşen köylere ait nüfus verileri kullanılmıştır. Kriging yöntemi kullanılarak yağış tahmin modeli oluşturulmuştur. Yağış modeli Çapraz Geçerlilik (Cross Validation) yöntemi ile test edilmiştir. Türkiye'nin yıllık ortalama toplam yağış tahmin haritası, orografik uzanış ve bakı koşullarını iyi bir şekilde yansıtmaktadır. Ayrıca, Türkiye genelinde yıllık ortalama toplam yağış miktarı $559.2 \mathrm{~mm}$, toplam yağış miktarı 433.9 milyar $\mathrm{m}^{3}$ olarak hesap edilmiştir. Bu değer, Türkiye gibi kullanılabilir su açısından sınırda bulunan bir ülke için oldukça önemlidir. Çalışmada daha sonra 26 havzaya düşen yıllık ortalama toplam yağış miktarı ve kişi başına düşen su miktarı hesap edilmiştir. Su potansiyellerinin karşılaştırılmasında kullanılan Falkenmark su stres indisine göre, Türkiye'de "mutlak su kıtlığı" gösteren Marmara, "su kıtığı" olan Küçük Menderes ve "su sıkıntısı" olan Sakarya Havzalarının dışında kalan diğer 23 havza, "su baskısı yok" kategorisine girmektedir. Türkiye nüfusunun büyük bir kısmının yer aldığı, sanayi ve tarım sektörüne ait büyük yatırımların bulunduğu bu üç havzada mutlak su kıtlığı ve su kıtlığının yaşanması özellikle bu havzalar için geleceğe yönelik su kullanım planlarının yapılmasını zorunlu kılmaktadır.

Water is one of the world's most important natural resources. Rapid population growth, urbanization and industrialization are increasing the demand for water with each passing day. This situation will lead to the emergence of big problems in country's access to water resources in the near future. It is important to correctly calculate the water potentials of the countries in planning the precautions that can be taken against possible water scarcity to be experienced in the future. The most important factor in determining the water potential is the rainfall that varies on spatial and temporal scales. It is difficult to be able to accurately estimate the precipitation and to reveal its spatial distribution. Different methods are used to overcome this difficulty and to predict the precipitation accurately. The geostatistical methods are mostly preferred among these methods. The purposes of this study which was carried out using geostatistical methods are to calculate Turkey's precipitation realistically, to create the right precipitation forecast model, to calculate the annual mean total precipitation for each basin, to determine the amount of water per person in 26 basins, and to evaluate each basin according to Falkenmark water stress index. For this purpose, the annual mean total precipitation data covering 1975-2010 period and population data of villages falling within the boundaries of 26 river basins have been used. A precipitation prediction model was constructed by using Kriging method. The precipitation model was tested with the Cross Validation method. Turkey's annual mean total precipitation estimation map well reflects the orographic stretch and aspect conditions. Also, the annual mean total amount of precipitation is $559.2 \mathrm{~mm}$ and the total amount of precipitation is 433.9 billion $m 3$ across Turkey. This value is very important for a country, which is at the border in terms of available water like Turkey. In the study, the amount of 
annual mean total precipitation and the amount of water per capita were then calculated for 26 basins. According to Falkenmark water stress index used in the comparison of water potentials, the other 23 basins out of Marmara showing "absolute water scarcity", Küçük Menderes with "water scarcity" and Sakarya basin with "water shortage" in Turkey fall into the category of "no water pressure". The fact that absolute water scarcity and water scarcity are experienced in these three basins where the large part of the population of Turkey live and where there are large investments on industrial and agricultural sectors requires making water use plans for the future especially for these basins.

\section{Giriş}

Su, ferah ve zenginliğin anahtarı olarak görüldüğünden, dünyanın en önemli doğal kaynaklarından biri olarak tanımlanır (Arbués vd., 2003). Su kaynaklarının dağılımı, toplumun işleyişinde kritik bir öneme sahiptir. Eskiden beri birçok toplum su sıkıntısı problemini çözmek için çeşitli şekillerde mücadele etmiştir. Su kaynaklarının dağılımı doğal süreçlerin ve insan müdahalesinin kombinasyonundan etkilenmektedir. Su kıtlığı problemi, su kaynaklarının kirliliği ve aşırı kullanımı sonucu ortaya çıkmaktadır (Postel, 2000; Postel, vd., 1996). Bu sebeple, suyu her açıdan konu alan çok sayıda çalışmalar mevcuttur (Vörösmarty, vd., 2000; Gleick, 2003; Burte, vd., 2005; Taddei, vd., 2008; Henrique ve Chaves Suzana, 2007; Vörösmarty, vd., 2010; Mancosu, vd., 2015). İklim değişikliği ve bunun sonucu oluşan kuraklık, patlayan nüfus artışı, tek başına israf, su kaynaklarını sürekli tehdit altında bırakmaktadır. Su kaynaklarının giderek kurumaya başlaması, susuzluk tehlikesini artırmaktadır. Yakın gelecekte de dünyada özellikle kurak ve yarı-kurak iklim kuşaklarında yer alan ülkelerin su kaynaklarına ulaşmasında büyük problemler yaşanacaktır ve bu su kıtlığının sosyal, ekonomik ve politik yaşama olan olumsuz etkilerini kaçınılmaz bir hale getirecektir. Dünyada su kıtlığının nedenleri, yenilenebilir kaynak miktarının kıtlığı, yüksek nüfus artışının kişi başına düşen kaynakları azaltması ve suyun kullanım şeklindeki yanIışlar şeklinde sıralanabilir. Yenilenebilir su potansiyelinden daha fazla suyun tüketilmesi durumunda yeralt su rezervleri tüketilmeye başlamakta ve kullanılabilir su kaynakları azalmaktadır. Nüfus yoğunluğunun artması ve su kaynaklarının dünya genelinde dengeli dağılmaması kişi başına düşen su miktarını azaltmaktadır. Ayrıca artan nüfus, kentleşme ve kişi başına tüketilen suyun artması nedeniyle suya olan talep mevcut su kaynaklarını sürekli kirletmektedir. Gelişmiş ülkeler, kişi başına düşen su miktarı oranlarına göre $8.000-10.000 \mathrm{~m}^{3}$ su zengini ülkeler arasındadır. Türkiye'nin konumu itibarı ile daha kuzeyde olması, Fırat ve Dicle nehirlerinin Türkiye sınırları içerisinden çıkması, su zengini bir ülke olarak adlandırılmasını sağlamaktadır (Erdağ, 2015). Ancak su zengini ülkelerle karşılaştırıldığında Türkiye kişi başına düşen yıllık $1.519 \mathrm{~m}^{3}$ su miktarıyla su sıkıntısı olan ülkeler kategorisinde yer almaktadır (DSi, 2014). Kişi başına düşen su miktarı, bir kişinin su ihtiyacını karşılamak için ne kadar suya ihtiyacı olduğunun tespit edilerek, her kişi için su kıtlık ölçüsünün belirlenmesiyle hesap edilir (Rijsberman, 2006). Farklı yöntemlerle yapılan çalışmalarda Türkiye'de kişi başına düşen yıllık kullanılabilir su miktarı $1.555 \mathrm{~m}^{3}$ olarak hesaplanmıştır (Burak, vd., 1997, Akın ve Akın, 2007). Bu durumda Türkiye su azlığı çeken ülkeler arasına girmektedir. Kişi başına düşen yıllık ortalama su miktarının Asya için $3.000 \mathrm{~m}^{3}$, Bat Avrupa için $5.000 \mathrm{~m}^{3}$, Afrika için $7.000 \mathrm{~m}^{3}$, Kuzey Amerika için $18.000 \mathrm{~m}^{3}$, Güney Amerika için $23.000 \mathrm{~m}^{3}$ ve dünya ortalamasının da $7.600 \mathrm{~m}^{3}$ olduğu düşünüldüğünde, Türkiye'nin ortalamanın bile çok uzağında olduğu görülmektedir (Uluatam, 2004). Türkeş (2012), Türkiye'nin birçok bölgesinde etkili olan kuraklık olaylarının ve su sıkıntısının, yalnız tarım ve enerji üre- timi açısından değil, sulamayı, içme suyunu, öteki hidrolojik sistemleri ve etkinlikleri içeren su kaynakları yönetimi açısında da kritik bir noktaya ulaştğ̆ını belirtmiştir.

Ülkenin su potansiyeli, bulunduğu yerin konumuna, jeolojik, topografik yapısına ve bitki örtüsüne göre oluşmaktadır. Türkiye bu özellikler altında 26 su havzasına ayrılmış olup, bu havzaların yer alt ve yüzey suyu potansiyelinde önemli farklılıklar bulunmaktadır. Yağış, su potansiyelini etkileyen en önemli unsurdur. Türkiye'nin topografik yapısı, kısa mesafede değişmesi, kıyılara paralel yüksek dağ sıralarının varlığı, farklı iklim tiplerinin görülmesi gibi pek çok sebep su havzalarına düşen yağışı etkilemektedir. Bu durum, su havzalarının su potansiyellerinde farklılıklara yol açmaktadır. Bir ülkenin su varlığının gerçeğe yakın olarak hesaplanması, yıllık ortalama toplam yağış miktarının ve yağışın alansal dağılışının iyi bilinmesiyle mümkündür. Türkiye'de istasyon ağının özellikle dağlık alanlarda yetersiz olması, bu değerin hesaplanmasında en önemli sorunu oluşturmaktadır. Bu çalışmanın amacını,

- Türkiye yıllık ortalama toplam yağış değeri kullanılarak, doğru yağış tahmin haritasının oluşturulması,

- Yağış tahmin haritası kullanılarak, Türkiye'nin 26 su havzasına düşen yıllık ortalama toplam yağış miktarlarının hesaplanması,

- Türkiye'nin 26 su havzasına düşen kişi başı yıllık kullanılabilir su miktarının hesaplanması,

- 26 su havzası için Falkenmark su kıtlık indisine göre değerlendirilmelerin yapılması oluşturmaktadır.

\section{Veri ve Yöntem}

\section{1. Çalışma Alanı}

Türkiye Akdeniz Havzasında yer almaktadır. Bulunduğu konum, üç tarafinın denizlerle çevrili olması, deniz seviyesine göre yüksek olması, kıyılara paralel dağ sıralarının bulunması, denize yakınlık ve uzaklık, yer şekillerinin kısa mesafelerde değişmesi ve çeşitlilik göstermesi gibi faktörler Türkiye ikliminde bölgesel değişikliklerin ortaya çıkmasına neden olmaktadır. Bundan başka, Türkiye soğuk ve sıcak karakterli kütlelerin hareket alanı içinde bulunmaktadır. Kış aylarında etkili olan Kontinantal Polar, Maritim Polar ve Maritim Tropikal ile yaz aylarında etkili olan Kontinantal Tropikal hava kütlelerinin de Türkiye'de iklimsel şartların oluşmasında etkisi vardır. Bu koşullar altında, sıcaklık değerleri ile yağış miktarları farklı bölgelerde değişik değerlerde karşımıza çıkar. Şekil 1 Türkiye'de 1975-2010 dönemine ait yıllık ortalama toplam yağış değerlerinin coğrafi dağııışını göstermektedir. Buna göre, i̇ç Anadolu, Konya Ovası ve Tuz Gölü çevresi, Doğu Anadolu'nun yüksek dağlarla çevrili bazı depresyonları ve Güneydoğu Anadolu platoları ile ovaları, 255$400 \mathrm{~mm}$ arasında yıllık ortalama toplam yağış değerine sahip alanları oluşturmaktadır. Bu alanlar yağışın en düşük olduğu 
bölgelerdir. Karadeniz ve Akdeniz kıyı kuşağı, yıllık ortalama toplam yağış değerlerinin en yüksek olduğu yerlerdir. Öte yandan, yıllık ortalama toplam yağış miktarları farklı bölgelerde, 401-600 mm, 601-800 mm, 801-1200 mm arasında değişen değişik değerler ile izlenmektedir (Şekil 1). Türkiye'de yağışın mevsimlere ve bölgelere göre biçimi, tutarı, süresi değişiklikler göstermektedir. Bundan başka Türkiye nehirlerinin akışları düzensizdir. Yıllık ortalama yağış, buharlaşma ve yüzey akışı coğrafi olarak büyük ölçüde değişkenlik gösterir (Yuksel, 2015). Bu sebeple, hidrolojik su havzalarının verimleri ve su potansiyelleri farklıdır. Yıllık ortalama yağış miktarı $643 \mathrm{~mm}$ olan Türkiye'nin 779.500 km² yüzölçümü dikkate alındığında toplam yağış 501 milyar $\mathrm{m}^{3}$ suya karşılık gelmektedir (Çiçek ve Ataol, 2009). Bu suyun 274 milyar $\mathrm{m}^{3}$ 'ü toprak ve su yüzeyleri ile bitkilerden olan buharlaşma yoluyla atmosfere geri dönmekte, 69 milyar $\mathrm{m}^{3 \prime}$ lük kısmı yeraltı suyunu beslemekte, 158 milyar $\mathrm{m}^{3 \prime}$ lük kısmı ise akışa geçerek çeşitli büyüklükteki akarsular vasıtasıyla denizlere ve kapalı havzalardaki göllere boşalmaktadır (Çiçek ve Ataol, 2009).

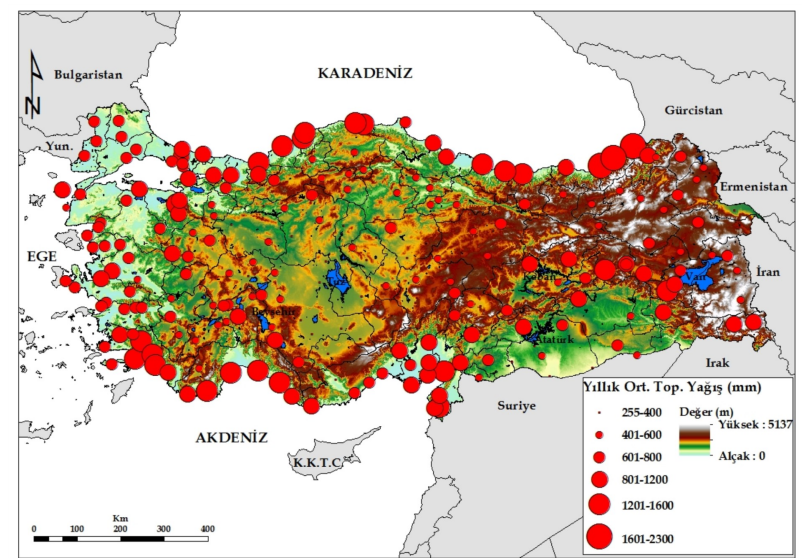

Şekil 1. Türkiye'de 1976-2010 dönemine ait yıllık ortalama toplam yağış dağılış haritası.

Figure 1. The annual mean total precipitation distribution map for the period 1976-2010 in Turkey.

\section{2. Çalışmada Kullanılan Veri}

Çalışmada Türkiye'nin yıllık ortalama toplam yağışın dağılışını belirleyebilmek için uzun süreli yağış gözlemi yapan 228 meteoroloji istasyonundan elde edilen 1975-2010 dönemine ait yıllık ortalama toplam yağış verileri kullanılmıştır (Şekil 2). Veriler Meteoroloji Genel Müdürlüğü (MGM)'den elde edilmiştir. 36 yıllık dönem için ölçüm yapan istasyonların yıllık ortalama toplam yağış değerleri hesap edilmiştir. Kişi başına düşen yıllık kullanılabilir su miktarını hesap edebilmek için, çalışmada 26 akarsu havza sınırları içerisine düşen köylere ait nüfus verileri kullanılmıştır. Bu veriler Türkiye İstatistik Kurumu'ndan (TÜiK) temin edilmiştir.

\section{3. Çalışmada Kullanılan Yöntemler}

\section{Kriging Enterpolasyon Yöntemi}

Kriging enterpolasyon yöntemi, ölçümü yapılmış lokasyonlardan, ölçüm yapılmamış olan lokasyonlardaki değişkenlerin değerini tahmin etmek için kullanılan bir enterpolasyon

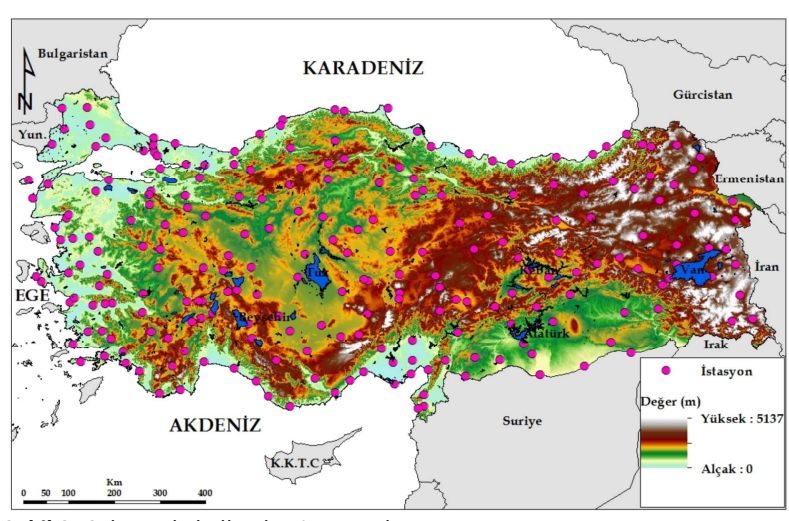

Şekil 2. Çalışmada kullanılan istasyonlar.

Figure 2. Stations used in study.

metodudur. Son yıllarda, Kriging tekniği jeoistatistik alanında yaygın olarak kullanılmaktadır (Caruso ve Quarta, 1998; Kalkhan, 2011). Kriging yöntemi en iyi doğrusal yansız tahmin edici olarak bilinmektedir. Yöntemin en büyük özelliği, tahmin edilen her bir nokta veya alan için bir varyans değerinin hesaplanabilmesidir. Genel olarak tahmin işlemi, bilinen değerlerin ağırlıklı ortalaması ile yapılmaktadır. Temel eşitlik,

$$
\hat{Z}\left(X_{0}\right)=\sum_{i=1}^{N} W_{i} Z\left(X_{i}\right)
$$

biçiminde gösterilir. Bu eşitlikte $\hat{Z}\left(X_{0}\right), X_{0}$ noktasına ilişkin Kriging değerini; $\left(X_{i}\right)$ değişkenlerin her bir $X_{i}$ noktasında gözlenen değerleri; $W_{i}$, her bir $Z\left(X_{i}\right)^{\prime}$ ye karşılık gelen değerlerini; $N$ ise, $\hat{Z}\left(X_{0}\right)$ 'ın Kriging tahmininde kullanılacak nokta sayısını ifade etmektedir. Gözlem verilerinin deneysel yarıvariogram yapısının belirlenmesi ve bu yapıya teorik bir yarıvariogram modelin uydurulması Kriging analizlerinin temelini oluşturmaktadır. Bu konuyla ilgili ayrıntılı bilgiler Aydin ve Çiçek (2015), Aydin vd. (2015) çalışmalarında verilmiştir. Teorik yarıvariogram, deneysel yarıvariograma matematiksel bir fonksiyon oturtularak elde edilmektedir. Nested model, deneysel bir yarıvariograma tek teorik modelin tam olarak oturtulamadığı durumlarda birden fazla teorik modellerin ard arda kullanılmasıyla oluşan teorik yarıvariogramların genel adıdır (Aydin, 2014). Böylece deneysel yarıvariogramı açıklayan daha iyi bir teorik yarıvariogram modeli elde edilmiş olur. Bu modeller oluşturulurken, verideki kontrolsüz etki (birbirine en yakın iki örnek arasındaki uzaklıkta, değerler arasındaki farkın değişimi, veri olmadığından belirlenemez ve bu durum yarıvariogramın orjininde bir süreksizliğe yani 0'dan farklı pozitif bir değer alması) tüm Nested yapıya dâhil edilebilmektedir. Tesadüfi alanlardaki toplam yarıvariogramlar, Nested yapıdaki her bir ölçeğin yarıvariogramların toplamıyla gösterilebilmektedir. Bu çalışmada Nested yarıvariogram Aydin (2014)'ün farklı teorik yarıvariogramlar kullanılarak elde ettiği yağış modellerinde, bu teorik yarıvariogramın yüksek performans sonucu vermesinden dolayı tercih edilmiştir. Nested model, Hole ve Mátern olmak üzere iki tip matematiksel modelin uygulanması ile gerçekleştirilmiştir.

Hole model, şeklinde ifade edilir.

$$
\gamma(h)=A\left[1-\left(1-\frac{h}{B}\right) e^{-h / B}\right]
$$


Mátern model,

şeklinde ifade edilir (Handcock ve Stein, 1993; Stein, 1999).

$$
\gamma(\mathbf{h})=\sigma^{2}\left\{1-\frac{2^{1-v}}{\Gamma(v)}\left(\frac{|\mathbf{h}|}{\alpha}\right)^{v} K_{v}\left(\frac{|\mathbf{h}|}{\alpha}\right)\right\}
$$

$\sigma^{2}>0$, varyansı, $\alpha>0$ etki uzaklığı parametresini, $v>0$ ise, şekil parametresini, $\Gamma\left(\right.$.) gamma fonksiyonunu, $\mathrm{K}_{\mathrm{v}}($.) modifiye Bessel fonksiyonunu, v ve $|\mathbf{h}|$ ise $\mathbf{h}$ vektörünün normunu ifade eder.

Çalışmada kullanılan Çapraz Geçerlilik yöntemi, teorik yarıvariogram parametrelerinin çalışma alanını temsil edip edemeyeceğinin belirlenmesinde bir ölçüttür. Kriging analizi sonucunda gerçek değerlerle, tahmin değerlerini karşılaştıran, seçilen modelin güvenirliliğini test eden bir yöntemdir. Ayrıca bu çalışmada, Belirleyicilik Katsayısı $\left(R^{2}\right)$, Kök Ortalama Kare Hata (RMSE), Ortalama Hata (ME) ve Ortalama Mutlak Hata (MAE) performans ölçümlerinden faydalanılmıştır.

\section{Falkenmart Su Stres Indisi}

1989 yılında hazırlanan Falkenmark indisi yaygın olarak kullanılan su stresi ölçümlerinden biridir. Bu indis ile ülkelerin toplam nüfusları ve toplam su kaynakları ilişkilendirilmiş, doğal sistemin ihtiyaçları da göz önünde bulundurularak, nüfusun su kaynakları üzerindeki baskısı ortaya konulmuştur. Falkenmark indisine göre, kişi başına düşen yıllık su kullanım miktarının $1.700 \mathrm{~m}^{3}$ değerinin altına indiğinde o ülke su kıtlığı çekmektedir. Bu değer kişi başına 1.700 ile $1.000 \mathrm{~m}^{3}$ aralığında olduğunda, periyodik veya sınırlı su kıtlığı içine girileceği anlaşılmaktadır. $1.000 \mathrm{~m}^{3}$ eşik değerinin altında, su kıtlığı ile karşı karşıya kalacağı, $500 \mathrm{~m}^{3}$ ün altında ise, giderek ağırlaşan sorunlarla mücadeleyi gerektiren kronik su kıtlığı yaşanacağını ifade etmektedir (Falkenmark, 1989; Tablo 1).

Tablo 1. Falkenmark su stres indisi.

Table 1. Falkenmark water stress index.

\begin{tabular}{cc}
\hline Su (m³ $/$ kişi/yıl) & Sınıflandırma \\
\hline$>1.700$ & Su baskısı yok \\
$1.000-1.700$ & Su sıkıntısı \\
$500-1.000$ & Su kıtlığı \\
$<500$ & Mutlak su kıtlığı \\
\hline
\end{tabular}

\section{Bulgular}

3.1. Türkiye'de Yıllık Ortalama Toplam Yağış Tahmini Nested tip teorik yarıvariogram modeli Şekil 3'de gösterilmektedir. Teorik yarıvariograma oturan yıllık ortalama toplam yağış değişkeninde ilk yarıvariogram tipi Hole olarak ayarlanmıştir. Bu modele ait eşik değer 0.04, etki uzaklığı 2 km'dir. Daha sonra Mátern tip teorik yarıvariogramı oluşturulmuştur. Bu modelin eşik değeri 0.16 etki uzaklığı, 119.1 km'dir (Tablo 2). Bu etki uzaklığı ve eşik değerinden sonra gözlemler arası bir etkileşim yoktur. Oluşturulan teorik yarıvariogramın parametreleri belirlendikten sonra gözlemi bulunmayan yerlerin tahmini için Kriging tahmin yöntemi kullanılmıştır. Tablo 3 yıllık ortalama toplam yağış değişkeni için, gözlemlenen ve tahmin edilen değerlerin tanımsal istatistik analiz sonuçlarını göstermektedir. Nested (Hole\&Mátern) teorik yarıvariogram sonucu oluşturulan Kriging modelinin performans değerleri Tablo 4'de gösteril- mektedir. Sonuçlar yüksek $\mathrm{R}^{2}$ değeri ve düşük RMSE, ME ve MAE değerleri vermektedir.

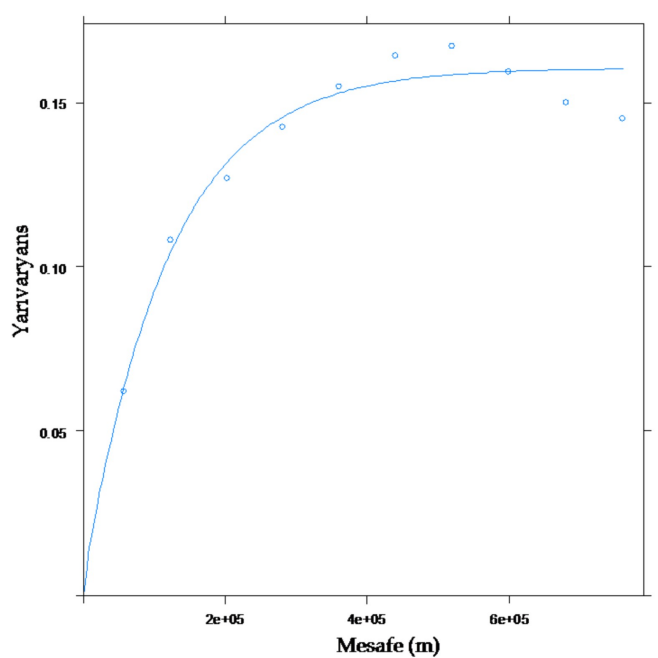

Şekil 3. Türkiye'de yıllık ortalama toplam yağışın deneysel ve teorik yarıvariogram modeli.

Figure 3. The experimental and theoretical semivariogram model of the annual mean total precipitation in Turkey.

Tablo 2. Teorik yarıvariogram sonucu.

Table 2. Theoretical semivariogram results.

\begin{tabular}{lcc}
\hline Model & Eşik değer & Etki uzaklığı (km) \\
\hline Hol & 0.04 & 2 \\
Mat & 0.16 & 119.1 \\
\hline
\end{tabular}

Tablo 3. Türkiye'nin yıllık ortalama toplam yağış için ölçülen ve tahmin edilen değerlerin tanımsal istatistik analiz sonuçları.

Table 3. Descriptive statistical analysis results of the values measured and estimated for Turkey's annual mean total precipitation.

\begin{tabular}{lcc}
\hline & Tahmin edilen & Gözlemlenen \\
\cline { 2 - 2 } & Nested yöntemi & \\
\hline Minimum & 300.7 & 258.6 \\
Birinci Bölen & 466.9 & 439.2 \\
Ortanca & 582.3 & 564.6 \\
Ortalama & 605.9 & 624.7 \\
Üçüncü Bölen & 690.4 & 727.9 \\
Maksimum & 1785.0 & 2249.9 \\
\hline
\end{tabular}

Tablo 4. Kriging modelinin performans değerleri.

Table 4. The performance values of the Kriging model.

\begin{tabular}{lcccc}
\hline & $\mathbf{R}^{\mathbf{2}}$ & RMSE (mm) & ME & MAE \\
\hline Ordinary Kriging (Nested) & 0.62 & 183.44 & -18.84 & 113.78 \\
\hline
\end{tabular}

Şekil 4'de Türkiye'nin yıllık ortalama toplam yağış tahmin haritası görülmektedir. Buna göre, yağış dağılışı, orografik uzanış ve bakı koşulunu iyi bir şekilde yansıtmaktadır. Örneğin, Bursa, Uludağ-Zirve ve Tunceli, Bitlis çevresi gibi yüksek yağışlı alanlar ile Karadeniz Bölgesi ve Ege Bölgesi'nde bakı ve orografik koşullar iyi tahmin edilmiştir. Diğer taraftan, Sakarya Havzası, Kızılırmak Havzası ve Konya Kapalı Havzası'nda kalan alanları bütüncül olarak yansımaktadır. Bu alanların yıllık ortalama toplam yağış değerleri, 300 mm'den az, 400 mm'den düşük bir değerde izlenmektedir (Şekil 4). Ülkenin yüksek dağlarla çevrili havzaları, batıan gelen nemli hava kütlelerinin etkilerinden uzak olan Güneydoğu Anadolu plato ve ovalarının bulunduğu alanlarda, yıllık ortalama toplam yağış değerleri $600-900$ mm 


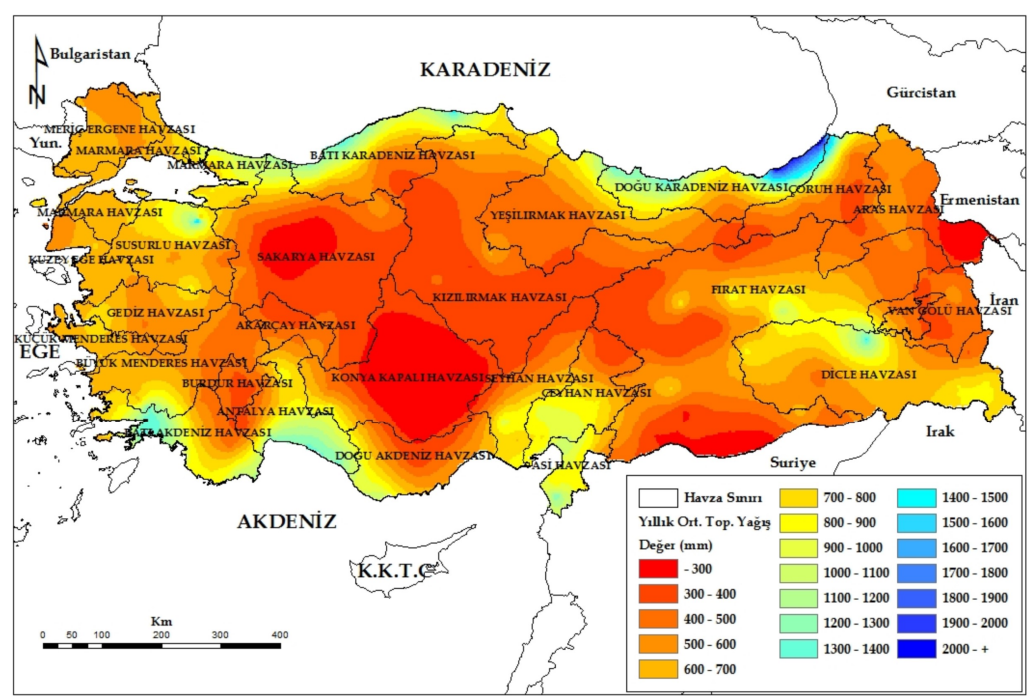

Şekil 4. Nested teorik yarıvariogram kullanılarak elde edilen Türkiye yıllık ortalama toplam yağış tahmin haritası.

Figure 4. Turkey's annual mean total precipitation estimation map obtained using Nested theoretical semivariogram.

arasında tahmin edilmiştir. Yıllık ortalama toplam yağış değerlerinin yüksek olduğu yerler, Karadeniz ve Akdeniz kıyı kuşağıdır. Özellikle, Doğu Karadeniz Havzası'nın doğu kesimi, 2000 $\mathrm{mm}$ 'den yüksek yıllık ortalama toplam yağış değerine sahiptir.

\subsection{Havzaların Su Potansiyelinin Hesaplanması}

Türkiye su zengini bir ülke olmadığından su potansiyelinin doğru hesaplanması büyük önem taşımaktadır. Su potansiyelinin hesaplanması; kaynakların kontrol edilmeyişi, kaynakların bölgelere dengesiz dağılmış olması, yağışların düzensizliği, su kaynakları planlanmasının bölgesel olarak ve kısa vadeli yapılması nedeniyle zorlaşmaktadır.

Türkiye'nin 779.425 km²'lik yüzölçümünün 765.52 km²'lik bölümünü kara, $14.300 \mathrm{~km}^{2}$ 'lik bölümünü sulu yüzey oluşturmaktadır. Türkiye'nin yağış rejimi mevsimlere ve bölgelere göre çok büyük farklılık göstermekte olup, yıllık ortalama toplam yağış 643 mm'dir. Bu da yılda ortalama 501 milyar $\mathrm{m}^{3}$ suya karşılık gelmektedir. Bu miktarın 274 milyar mün $^{3 \prime}$ toprak ve su yüzeylerinden ve bitkilerden olan buharlaşmalar yoluyla atmosfere geri döndüğü; 41 milyar $\mathrm{m}^{3 \prime}$ nün yüzeyden sızmalar suretiyle yeralt su rezervlerini beslediği; 186 milyar $\mathrm{m}^{3 \prime}$ nün ise çeşitli büyüklükteki akarsular aracılığı ile denizlere, kapalı havzalardaki göllere boşalmak sureti ile akışa geçtiği kabul edilmektedir. Komşu ülkelerden doğan akarsular ile yılda 7 milyar $\mathrm{m}^{3}$ suyun Türkiye su potansiyeline dahil olduğu göz önünde bulundurulduğunda, toplam yenilenebilir su potansiyelimiz brüt 234 milyar $\mathrm{m}^{3}$ olmaktadır (DPT, 2001).

Bu çalışmada, Kriging tekniği kullanılarak elde edilen yıllık ortalama toplam yağış tahmin haritası ile 26 havzanın yağış miktarları hesap edilmiştir. Tablo 5, Devlet Su İşleri Genel Müdürlüğü (DSi) tarafindan 2006 yılında hesaplanan havzalara düşen yıllık ortalama toplam yağış değerlerini, Kriging yöntemi kullanılarak 1975-2010 dönemine ait elde edilen tahmin haritasından havzalara düşen yıllık ortalama toplam yağış değerlerini ve bu değerlerin karşılaştırılmasını göstermektedir. Şekil 5, Tablo 5'e göre Nested (Hole\&Mátern) teorik yarıvariogram kullanılarak elde edilen yıllık ortalama toplam yağış tahmin haritasından hesaplanan su potansiyeli değeri, DSi'nin hesapladığı değere göre daha düşük çıkmıştır. Benzer durum 19 havzada görülmektedir.

Modelden elde edilen havza yağış ortalamaları ile DSI'nin havza yağış ortalamaları kıyaslandığında, genellikle plato sahalarının yaygın olduğu havzaların büyük bir kesimi ve iç bölgelerde kalan havzalarda yağış değerleri yüksek veya DSi'nin değerlerine yakın sonuçlar vermiştir. Örneğin Kızılırmak, Yeşilırmak, MeriçErgene, Burdur, Van Gölü, Aras, Akarçay havzalarında yağış değerleri DSi'nin değerlerinden yüksek, Konya gibi havzalarda yakındır. Bunun dışında Doğu ve Batı Karadeniz, Antalya, Doğu Akdeniz gibi yüksek dağ sıralarının çevrelediği havzalarda yani yükselti etkisinin bulunduğu alanlarda düşük değerler vermiştir.

Tablo 5. Havzalara düşen yıllık ortalama toplam yağış miktarı ve karşılaştırılması.

Table 5. Annual mean total precipitation amount falling on basins and their comparison.

\begin{tabular}{lcccc}
\hline Havza Adı & DSi (mm) & OK (mm) & DSí-0K (mm) & DSi-OK (\%) \\
\hline Akarçay Havzası & 455.8 & 462.3 & 6.5 & 1.4 \\
Antalya Havzası & 1000.4 & 757.4 & -243 & -32.1 \\
Aras Havzası & 432.4 & 469.9 & 37.5 & 8.0 \\
Asi Havzası & 815.6 & 796.9 & -18.7 & -2.3 \\
Batı Akdeniz Havzası & 875.8 & 731.8 & -144 & -19.7 \\
Batı Karadeniz Havzası & 811 & 702.7 & -108.3 & -15.4 \\
Burdur Havzası & 446.3 & 468.8 & 22.3 & 4.8 \\
Büyük Menderes Havzası & 664.3 & 586.3 & -78 & -13.3 \\
Ceyhan Havzası & 731.6 & 647.3 & -84.3 & -13.0 \\
Çoruh Havzası & 629.4 & 570.9 & -58.5 & -10.2 \\
Doğu Akdeniz Havzası & 745 & 567.5 & -177.5 & -31.3 \\
Doğu Karadeniz Havzası & 1198.2 & 903.9 & -294.3 & -32.6 \\
Dicle Havzası & 807.2 & 647.6 & -159.6 & -24.6 \\
Fırat Havzası & 540.1 & 508.2 & -31.9 & -6.3 \\
Gediz Havzası & 603 & 588.5 & -14.3 & -2.5 \\
Kızılırmak Havzası & 446.1 & 456.9 & 10.8 & 2.4 \\
Konya Kapalı Havzası & 416.8 & 382.7 & -34.1 & -8.9 \\
Küçük Menderes Havzası & 727.4 & 624.3 & -103.1 & -16.5 \\
Kuzey Ege Havzası & 624.2 & 606.2 & -18 & -3.0 \\
Marmara Havzası & 728.7 & 683.4 & -45.3 & -6.6 \\
Meriç Ergene Havzası & 504 & 595.2 & 91.2 & 15.3 \\
Sakarya Havzası & 524.7 & 444.7 & -80 & -18.0 \\
Seyhan Havzası & 624 & 553.9 & -70.1 & -12.7 \\
Susurluk Havzası & 711.6 & 662.0 & -49.6 & -7.5 \\
Van Gölü Havzası & 474.3 & 483.4 & 9.1 & 1.9 \\
Yeşilırmak Havzası & 496.5 & 533.9 & 37.4 & 7.0 \\
\hline
\end{tabular}

Not: Cizelgede DSi, DSİ tarafindan 2006 yilında hesaplanan yaăıs miktarını: OK, OK yöntemiyle oluşturulan 1975-2010 dönemine ait yıllık ortalama toplam yağıs̆ tahmin haritasından hesaplanan yağış miktarını göstermektedir. 


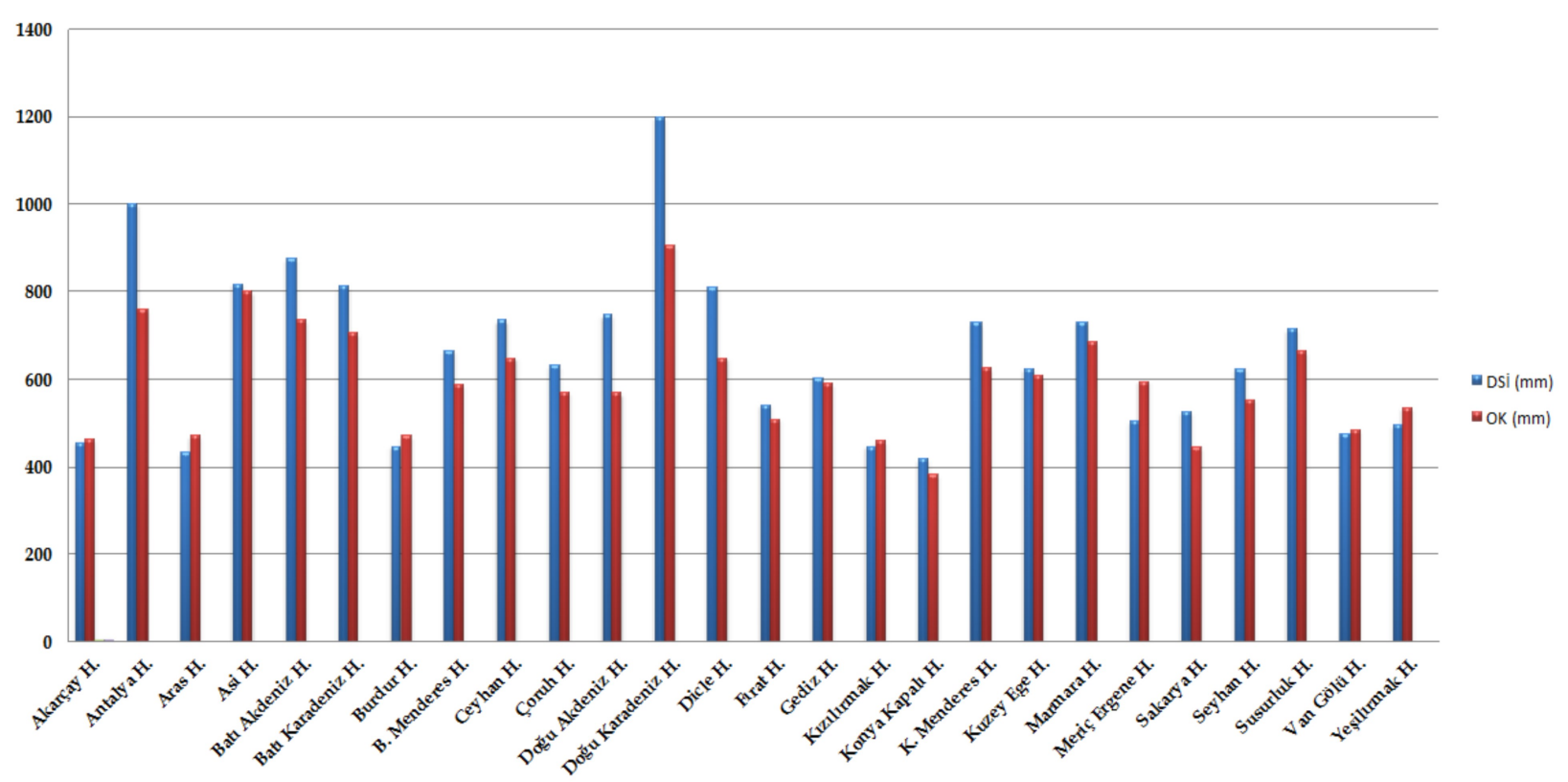

Şekil 5. Havzalara düşen yıllık ortalama toplam yağış miktarı (mm). Figure 5. Annual mean total precipitation amount falling on basins ( $\mathrm{mm}$ ).

\subsection{Kişi Başına Düşen Kullanılabilir Su Miktarı}

Havzaların hesaplanan su potansiyelleri o havzada yaşayan nüfusa bölündüğünde, kişi başına düşen yıllık ortalama su miktarına ulaşılmaktadır. DSi tarafindan hesaplanan havzalara düşen yıllık ortalama toplam yağış değerleri ile Kriging yöntemi kullanılarak elde edilen tahmin haritasından havzalara düşen yıllık ortalama toplam yağış değerlerinin \%45.3'lük miktarı hesap edilerek kişi başına düşen kullanılabilir su miktarı bulunmuştur. \%45.3 kullanılabilir yağış oranı DSi tarafindan yapılan uzun yıllık buharlaşmadan arta kalan değere karşılık gelmektedir. DSi tarafindan hesap edilen 501 milyar m $^{3 \prime}$ lük yağışın 274 milyar $\mathrm{m}^{3}$ ü buharlaşmakta (\%54.7), geri kalan 227 milyar $\mathrm{m}^{3}$ (\%45.3) yüzey akışı ve yeraltına sızma ile kullanılabilir su miktarını oluşturmaktadır (Tablo 6). Buna göre kullanılabilir su miktarının kişi başına en fazla düştüğü havza $16.508 .04 \mathrm{~m}^{3}$ ile Çoruh Havzasıdır. (DSi'nin hesabından $1.691 .58 \mathrm{~m}^{3}$ daha az). Havza yüzölçümünün küçük, nüfusunun az olması, kişi başına düşen kullanılabilir su miktarının fazla olmasına neden olmuştur. Batı Akdeniz Havzası, $6.811 .07 \mathrm{~m}^{3}$ değeri ile 2. sırada yer almaktadır. Batı Akdeniz Havzasını sırasıyla Aras Havzası $\left(6491.46 \mathrm{~m}^{3}\right)$, Burdur Havzası $\left(6052.39 \mathrm{~m}^{3}\right)$ takip etmektedir. Yüzölçümü bakımından küçük havzalardan biri olan Marmara Havzası'nda (24.100.00 km²) Türkiye nüfusunun yaklaşık \%20'si (17.5 milyon) yaşamaktadır. Bu havzanın kişi başı kullanılabilir su miktarı $426.33 \mathrm{~m}^{3}$ 'dür. DSi değerleri incelendiğinde 454.49 $\mathrm{m}^{3 \prime}$ lük bir değer gözlenmektedir. Her iki sonuç da, havzanın fazla nüfus barındırması, dolayısıyla su kaynakları üzerindeki baskının yoğun olması nedeniyle su ihtiyacının fazla olduğunu göstermektedir. Küçük Menderes ve Sakarya, $563.10 \mathrm{~m}^{3}$ ve $1492.19 \mathrm{~m}^{3}$ değerleri ile kişi başı kullanılabilir su miktarının düşük olduğu havzaları oluşturmaktadır.

\subsection{Falkenmark Su Stres Indisi Sonuçları}

Su kaynaklarının küresel dağılımına ilişkin olarak, bir ülkenin su zengini olup olmadığının ya da su kıtlığı yaşayıp yaşamadığının belirlenmesinde sadece coğrafi koşullar veya o ülkenin nüfusu etkili değildir. Bu durumun tespit edilmesinde farklı su kıtlığı indisleri mevcuttur. Bu çalışmada İşveçli hidrolojist Malin Falkenmark su stresi indisi kullanılmıştır (Tablo 7). Bu indise göre, Türkiye'de "mutlak su kıtı̆ğı" gösteren Marmara, "su kıtığı" olan Küçük Menderes ve "su sıkıntısı" olan Sakarya Havzalarının dışında kalan diğer 23 havza, "su baskısı yok" kategorisine girmektedir.

Türkiye nüfusunun yaklaşık \%40'ının yaşadığı ve sanayi faaliyetlerinin en yoğun olduğu Marmara, Küçük Menderes ve Sakarya Havzaları sırasıyla mutlak su kıtlığı, su kıtlığı ve su sıkıntısı yaşayan havzalardır. Bu nedenle İstanbul'un su problemini çözmek için başka havzalardan su transferi yapılmaktadır. Transfer yapılan havzalardan biri de su sıkıntısı yaşayan Sakarya Havzasıdır. Gelecekte bu su transferi iki havzada yaşayanlar arasında ciddi problemlere neden olabilecektir. Benzer şekilde, Konya Kapalı Havzası'nda sulu tarım alanlarının su ihtiyacını karşılamak içinde, farklı havzalardan su transferi yapılmaktadır.

\section{Tartışma ve Sonuç}

Su, sadece insanlar için değil, tüm canlılar için temel bir maddedir. Yaşam koşullarının değişmesi ile kullanım alanları genişlemiş olan suya talep, her geçen gün daha da artmaktadır. Su kaynakları iklim değişikliği, küresel ısınma, yanlış kullanım ve kirleticiler nedeniyle azalma tehlikesi ile karşı karşıyadır. Gerekli önlemler alınmadığı takdirde gelecekte dünyanın pek çok ülkesi ciddi anlamda su kıtlığı çekecektir. Bu sebeple, kuraklık ile ilgili çalışmaların, iklim değişikliği, gelecekteki sulama gereksinimleri ve verimliliği, iklim adaptasyon stratejileri üzerine su temini yönetimi, biyomoleküler ve genetik araştrrmalar üzerine stratejilerin ve politikarın geliştirilmesine yönelik çok sayıda araştirmalar yürütülmektedir (Mancosu, vd., 2015).

Türkiye'de pek çok ülke gibi, gerekli önlemler alınmadığında gelecekte ciddi bir su sıkıntısı ile karşı karşıya kalacaktır. Mevcut su kaynaklarının durumu, ülke nüfusunun büyüme hızı, suya 
Tablo 6. Havzalar için kişi başına düşen yıllık kullanılabilir su miktarı $\left(\mathrm{m}^{3}\right)$.

Table 6. The annual amount of available water per person for basins $\left(\mathrm{m}^{3}\right)$.

\begin{tabular}{|c|c|c|c|c|c|c|}
\hline Havza Adı & $\begin{array}{c}\text { Havza } \\
\text { Alanı } \\
\left(\mathrm{km}^{2}\right) \\
\end{array}$ & $\begin{array}{l}\text { Nüfus } \\
\text { (kişi) }\end{array}$ & $\begin{array}{c}\text { KSM } \\
\left(\mathrm{m}^{3}\right)^{*}\end{array}$ & $\begin{array}{c}\text { KSM } \\
\left(\mathrm{m}^{3}\right)^{* *}\end{array}$ & $\begin{array}{c}\text { Kişi başına } \\
\text { düşen KSM } \\
\left(\mathrm{m}^{3}\right)^{*}\end{array}$ & $\begin{array}{c}\text { Kişi başına } \\
\text { düşen KSM } \\
\left(\mathrm{m}^{3}\right)^{* *}\end{array}$ \\
\hline Akarçay Havzası & 7.605 .00 & 693.229 & 1.592 .653 .549 .50 & 1.570 .260 .627 .00 & 2.297 .44 & 2.265 .14 \\
\hline Antalya Havzası & 19.577 .00 & 2.325 .903 & 6.716 .911 .769 .40 & 8.871.928.352.40 & 2.887 .87 & 3.814 .40 \\
\hline Aras Havzası & 27.548 .00 & 831.250 & 5.863 .996 .755 .60 & 5.396 .025 .105 .60 & 7.054 .43 & 6.491 .46 \\
\hline Asi Havzası & 7.796 .00 & 1.653 .047 & 2.814.322.477.20 & 2.880 .363 .172 .80 & 1.702 .51 & 1.742 .46 \\
\hline Batı Akdeniz Havzası & 20.953 .00 & 1.220 .489 & 6.946 .032 .646 .20 & 8.312.838.742.20 & 5.691 .19 & 6.811 .07 \\
\hline Batı Karadeniz Havzası & 29.598 .00 & 1.943 .462 & 9.421 .727 .113 .80 & 10.873 .802 .034 .00 & 4.847 .91 & 5.595 .07 \\
\hline Burdur Havzası & 6.374 .00 & 212.917 & 1.353 .623 .433 .60 & 1.288 .656 .438 .60 & 6.357 .52 & 6.052 .39 \\
\hline Büyük Menderes Havzası & 24.976 .00 & 2.344 .089 & 6.633 .473 .246 .40 & 7.515.975.230.40 & 2.829 .87 & 3.206 .35 \\
\hline Ceyhan Havzası & 21.982 .00 & 1.972 .744 & 6.445 .713 .715 .80 & 7.285 .160 .133 .60 & 3.267 .38 & 3.692 .91 \\
\hline Çoruh Havzası & 19.872 .00 & 311.318 & 5.139 .250 .934 .40 & 5.665 .868 .870 .40 & 16.508 .04 & 18.199 .62 \\
\hline Doğu Akdeniz Havzası & 22.048 .00 & 1.821 .290 & 5.668 .044 .720 .00 & 7.440 .869 .280 .00 & 3.112 .10 & 4.085 .49 \\
\hline Doğu Karadeniz Havzası & 24.077 .00 & 2.284 .655 & 9.858 .729 .735 .90 & 13.068.624.814.20 & 4.315 .19 & 5.720 .17 \\
\hline Dicle Havzası & 57.614 .00 & 3.637 .528 & 16.901.804.359.20 & 21.067.227.422.40 & 4.646 .51 & 5.791 .63 \\
\hline Firat Havzası & 127.304 .00 & 8.301 .257 & 29.307.239.438.40 & 31.146 .871 .351 .20 & 3.530 .46 & 3.752 .07 \\
\hline Gediz Havzası & 18.000 .00 & 1.775 .938 & 4.798.629.000.00 & 4.916 .862 .000 .00 & 2.702 .03 & 2.768 .60 \\
\hline Kızılırmak Havzası & 78.180 .00 & 3.912 .522 & 16.181.360.226.00 & 15.798.872.394.00 & 4.135 .79 & 4.038 .03 \\
\hline Konya Kapalı Havzası & 53.850 .00 & 2.739 .185 & 9.335 .602 .935 .00 & 10.167.440.040.00 & 3.408 .17 & 3.711 .85 \\
\hline Küçük Menderes Havzası & 69.0700 & 3.468 .913 & 1.953 .354 .165 .30 & 2.275 .940 .765 .40 & 563.10 & 656.10 \\
\hline Kuzey Ege Havzası & 10.003 .00 & 841.538 & 2.746 .909 .825 .80 & 2.828 .474 .287 .80 & 3.264 .15 & 3.361 .08 \\
\hline Marmara Havzası & 24.100 .00 & 17.504 .219 & 7.460 .882 .820 .00 & 7.955.436.510.00 & 426.23 & 454.49 \\
\hline Meriç Ergene Havzası & 14.560 .00 & 1.225 .469 & 3.925 .748 .736 .00 & 3.324.222.720.00 & 3.203 .47 & 2.712 .61 \\
\hline Sakarya Havzası & 58.160 .00 & 7.851 .756 & 11.716 .279 .656 .00 & 13.823 .998 .056 .00 & 1.492 .19 & 1.760 .63 \\
\hline Seyhan Havzası & 20.450 .00 & 1.931 .960 & 5.131 .246 .515 .00 & 5.780 .642 .400 .00 & 2.655 .98 & 2.992 .11 \\
\hline Susurluk Havzası & 22.399 .00 & 3.202 .909 & 6.717 .146 .514 .00 & 7.220 .425 .165 .20 & 2.097 .20 & 2.254 .33 \\
\hline Van Gölü Havzası & 19.405 .00 & 1.100 .283 & 4.249 .310 .781 .00 & 4.169.317.549.50 & 3.862 .02 & 3.789 .31 \\
\hline Yeșilırmak Havzası & 36.114 .00 & 2.449 .920 & 8.734 .412 .863 .80 & 8.122 .562 .253 .00 & 3.565 .18 & 3.315 .44 \\
\hline
\end{tabular}

Not: Çizelgede *, OK yöntemiyle olușturulan yıllık ortalama toplam yağış tahmin haritasından hesaplanan $\mathrm{m}^{3}$ cinsinden kullanılabilir su miktarı

ve kişi başına düş̧en kullanılabilir su miktarını; **, DSİ tarafından yağış miktarı kullanılarak hesaplanmış $\mathrm{m}^{3}$ cinsinden kullanılabilir su miktarını

ve kişi başına düşen kullanılabilir su miktarını göstermektedir. Ayrıca, KSM Kullanılabilir Su Miktarını ifade etmektedir.

Tablo 7. Falkenmark su stres indisine göre havzalarda kişi başına düşen kullanılabilir su miktarı.

Table 7. The amount of available water per person in basins according to the Falkenmark water stress index.

\begin{tabular}{|c|c|c|c|}
\hline $\begin{array}{c}<500 \\
\text { Mutlak Su Kıtlık }\end{array}$ & $\begin{array}{l}500-1000 \\
\text { Su Kıtlığı }\end{array}$ & $\begin{array}{l}1000-1700 \\
\text { Su Sıkıntısı }\end{array}$ & $\begin{array}{c}>1700 \\
\text { Su Baskısı Yok }\end{array}$ \\
\hline Marmara & K. Menderes & Sakarya & $\begin{array}{c}\text { Asi } \\
\text { Susurluk } \\
\text { Akarçay } \\
\text { Seyhan } \\
\text { Gediz } \\
\text { B. Menderes } \\
\text { Antalya } \\
\text { Doğu Akdeniz } \\
\text { Meriç Ergene } \\
\text { Kuzey Ege } \\
\text { Ceyhan } \\
\text { Konya Kapalı } \\
\text { Firat } \\
\text { Yeşilırmak } \\
\text { Van Gölü } \\
\text { Kızılırmak } \\
\text { Doğu Karadeniz } \\
\text { Dicle } \\
\text { Batı Karadeniz } \\
\text { Batı Akdeniz } \\
\text { Burdur } \\
\text { Aras } \\
\text { Coruh }\end{array}$ \\
\hline
\end{tabular}

olan talebin giderek artması, plansız ve hatalı su kullanımı göz önünde bulundurulduğunda bu durum kaçınılmaz görülmektedir. TÜiK, Türkiye nüfusunun 2030 yılında 100 milyona ulaşacağını öngörmektedir (WWF, 2014). Bu durumda, kişi başına düşen su miktarının $1.120 \mathrm{~m}^{3} / \mathrm{yıl} \mathrm{olması} \mathrm{beklenmektedir.} \mathrm{Tür-}$ kiye, gelişen ekonomi ve büyüyen kentleriyle "su fakiri" olma yolunda ilerlemektedir (WWF, 2014). Su kaynaklarının gelişti- rilmesi ile ilgili çalışmaların, Türkiye'nin ekonomik kalkınma programında önemli bir unsurdur (Yuksel, 2015). Ayrıca, Türkiye için su kaynaklarının geliştirilmesi, yönetimi, kullanımı ve korunmasının, toplumun tüm ekonomik ve sosyal ihtiyaçlarını dikkate alarak entegre bir şekilde planlanması gerektiğide büyük önem arz etmektedir (Yuksel, 2015).

Bu çalışmada Türkiye'nin yağışını gerçeğe uygun hesaplamak için kullanılan Kriging analizi, havzaların su potansiyelini doğru hesaplamada önemli bir yöntem olmuştur. Havzaların sınıflandırılmalarında ve su potansiyellerinin karşılaştırılmasında kullanılan Falkenmark su stres indisi sonuçlarına göre, havzalardan 1'i mutlak su kıtlığı, 1'i su kıtlığı, 1'i su sıkıntısı, 23'ü su baskısı yok kategorilerine girmektedir. Türkiye'nin en fazla nüfusa sahip şehri İstanbul'un bulunduğu Marmara Havzası'nda mutlak su kıtlığı görülmektedir.

Her bir havzanın iklim ve topografik özellikleri birbirinden farklı olduğu gibi, su potansiyelleride farklıdır. Bu sebeple her bir havza için ayrı yağış modellerinin oluşturulması, her havza yağışını etkileyen yardımcı değiş̧enlerin (yükseklik, bakı, kıyıya uzaklık, eğim vb. gibi) kullanımı gerçeğe daha uygun su potansiyellerinin hesap edilmesine imkân tanıyacaktır. Bundan başka, alt havza bazında analiz yapmak ve gelişmiş teknikler (yapay zeka tabanlı) kullanmak, yağışın birincil etken olduğu bu araştırmaların doğruluk performansını yükseltecektir. Havzaların su potansiyellerinin gerçeğe uygun hesaplanması, havzalarda yapılacak planlamalar için önemlidir. 


\section{Kaynakça}

Akın, M., Akın, G. (2007) "Suyun önemi, Türkiye'de su potansiyeli, su havzaları ve su kirliliği", Ankara Üniversitesi Dil ve Tarih-Coğrafya Fakültesi Dergisi 47, 105-118.

Arbués, F., Valiñas, M.Á.G. and Espiñeira, R.M. (2003) "Estimation of residential water demand: a state-of-the-art review", Journal of Socio-Economics 32, 81-102.

Aydın O. (2014) Türkiye'de Yıllık Ortalama Toplam Yağışın Kriging Yöntemiyle Belirlenmesi, Ankara Üniversitesi, Sosyal Bilimler Enstitüsü, Doktora Tezi, Ankara.

Aydin O. and Çiçek I. (2015) Geostatistical Interpolation of Precipitation in Turkey, Lambert Academic Publishing, Saarbrucken, Germany.

Aydin O., Türkoğlu N. and Çiçek i. (2015) "The importance of geostatistics in physical geography", International Journal of Human Science 12(2), 1397-1415.

Burak, S., Duran Yıldız, i., Yetiş, Ü. (1997) Su Kaynaklarının Yönetimi, Ulusal Çevre Eylem Planı, Devlet Planlama Teşkilatı.

Burte, J., Coudrain, A., Frischkorn, H., Chaffaut, I. and Kosuth, P. (2005) "Human impacts on components of hydrological balance in an alluvial aquifer in the semiarid Northeast, Brazil", Hydrological Sciences Journal-Journal Des Sciences Hydrologiques, 50(1), 95-110.

Caruso, C. and Quarta, F. (1998) "Interpolation methods comparison", Computers and Mathematics with Applications 35(12), 109-126.

Çiçek, İ. ve Ataol, M. (2009) “Türkiye'nin su potansiyelinin belirlenmesinde yeni bir yaklaşım", Coğrafi Bilimler Dergisi 7(1), 51-64.

DSi (Devlet Su Iş̧leri Genel Müdürlüğü) (2014) 2014 Yılı Faaliyet Raporu, Ankara.

DPT (Devlet Planlama Teşkilatı) (2001) Su Havzaları, Kullanımı ve Yönetimi Özel ihtisas Komisyonu Raporu, Sekizinci Beş Yıllık Kalkınma Planı, Ankara.

Erdağ, R. (2015) “Türkiye'nin sınıraşan sular sorunu”, Yalova Sosyal Bilimler Dergisi 9, 27-52.

Falkenmark, M. (1989) "The massive water scarcity threatening Africa-why isn't it being addressed", Ambio 18(2), 112-118.

Gleick, P.H. (2003) "Global freshwater resources: soft-path solutions for the 21st century", Science, 302, 1524-1528.

Handcock, M.S. and Stein, M.L. (1993) "A bayesian analysis of kriging", Technometrics 35(4), 403-410.

Henrique, M.L., Chaves Suzana, A. (2007) "An integrated indicator based on basin hydrology, environment, life and policy: the watershed sustainability index", Water Resour Manage, 21, 883-895.

Kalkhan, M.A. (2011) Spatial Statistics: GeoSpatial Information Modelling and Thematic Mapping, CRC Press, USA.

Mancosu, N., Snyder, R.L., Kyriakakis, G. and Spano, D. (2015) "Water scarcity and future challenges for food production", Water, 7, 975992.

Postel, S.L., Daily, G.C. and Ehrlich, P.R. (1996) "Human appropriation of renewable fresh water", Science, 271(5250), 785-788.

Postel, S.L. (2000) "Entering an era of water scarcity: The challenges ahead", Ecological Applications, 10(4), 941-948.

Rijsberman, F.R. (2006) "Water scarcity: Fact or Fiction?", Agricultural Water Management 80, 5-22.

Stein, M.L. (1999) Interpolation of Spatial Data: Some Theory for Kriging, Springer-Verlag, New York.

Taddei, R., Muller, V., Pfaff, A., Broad, K., Lall, U. and Magalhaes Cordeiro, J.H. (2008) Impacts of water resource management choices in Ceará, Brazil: roles of streamflow forecasts, rainfall forecasts and participatory decision making., NOAA Office of Global Programs Grant Report., New York, USA.

Türkeş, M. (2012) “Türkiye'de gözlenen ve öngörülen iklim değişikliği, kuraklık ve çölleşme", Ankara Üniversitesi Çevre Bilimleri Dergisi, 4(2), 1-32.

Uluatam, Ö. (2004) Damlaya Damlaya [Ortadoğu'nun Su Sorunu], Türkiye İş Bankası Kültür Yayınları, İstanbul.

WWF. (2014) Türkiye'nin Su Riskleri Raporu, İstanbul.

Vörösmarty, C.J., Green, P., Salisbury, J. and Lammers, R. (2000) “Glo- bal water resources: vulnerability from climate change and population growth", Science, 289, 284-288.

Vörömarty, C.J., McIntyre, P.B., Gessner, M.O., Dudgeon, D., Prusevich, A., Green, P., Glidden, S., Bunn, S.E., Sullivan, C.A., Reidy Liermann, C. and Davies, P.M. (2010) "Global threats to human water security and river biodiversity", Nature, 467, 555-561.

Yuksel, I. (2015) "Water management for sustainable and clean energy in Turkey", Energy Reports, 1, 129-133. 